\title{
Contextual and Auditory Fear Conditioning are Mediated by the Lateral, Basal, and Central Amygdaloid Nuclei in Rats
}

\author{
Ki A. Goosens ${ }^{1}$ and Stephen Maren ${ }^{1,2,3}$ \\ ${ }^{1}$ Department of Psychology and ${ }^{2}$ Neuroscience Program, University of Michigan, Ann Arbor, Michigan 48109-1109, USA
}

\begin{abstract}
A large body of literature implicates the amygdala in Pavlovian fear conditioning. In this study, we examined the contribution of individual amygdaloid nuclei to contextual and auditory fear conditioning in rats. Prior to fear conditioning, rats received a large electrolytic lesion of the amygdala in one hemisphere, and a nucleus-specific neurotoxic lesion in the contralateral hemisphere. Neurotoxic lesions targeted either the lateral nucleus (LA), basolateral and basomedial nuclei (basal nuclei), or central nucleus (CE) of the amygdala. LA and CE lesions attenuated freezing to both contextual and auditory conditional stimuli (CSs). Lesions of the basal nuclei produced deficits in contextual and auditory fear conditioning only when the damage extended into the anterior divisions of the basal nuclei; damage limited to the posterior divisions of the basal nuclei did not significantly impair conditioning to either auditory or contextual CS. These effects were typically not lateralized, although neurotoxic lesions of the posterior divisions of the basal nuclei had greater effects on contextual fear conditioning when the contralateral electrolytic lesion was placed in the right hemisphere. These results indicate that there is significant overlap within the amygdala in the neural pathways mediating fear conditioning to contextual and acoustic CS, and that these forms of learning are not anatomically dissociable at the level of amygdaloid nuclei.
\end{abstract}

Many studies have attempted to delineate the neural circuitry that underlies Pavlovian fear conditioning (Davis 1992; Fanselow 1994; LeDoux 2000; Maren 2001). Consensus has emerged from these studies that the amygdala plays an essential role in this form of learning. For example, lesions of the amygdala have been shown to disrupt both the acquisition and expression of conditional fear (Kapp et al. 1979; LeDoux et al. 1990a; Sananes and Davis 1992; Falls and Davis 1995; Lee et al. 1996; Maren et al. 1996a; Maren 1999b). Furthermore, information concerning conditional and unconditional stimuli (CSs and USs) converges upon amygdaloid neurons (Romanski and LeDoux 1992; Romanski et al. 1993; LeDoux 1995; Shi and Davis 1999), and amygdala neurons exhibit associative plasticity during aversive conditioning (Maren et al. 1991; Quirk et al. 1995; Maren 2000).

The amygdala, however, is anatomically heterogeneous. It is composed of several nuclei that receive distinct sensory inputs (Pitkänen et al. 1997; Swanson and Petrovich 1998). Afferents relaying auditory information from the medial geniculate nucleus of the thalamus (MGN), thought to be the primary relay of auditory information to the amygdala (Quirk et al. 1997), terminate on the neurons of the lateral amygdaloid nucleus (LA; LeDoux et al. 1990b, 1991;

${ }^{3}$ Corresponding author.

E-MAIL maren@umich.edu; FAX (734) 763-7480.

Article and publication are at www.learnmem.org/cgi/doi/ $10.1101 / \mathrm{lm} .37601$.
Doron and LeDoux 1999), but not the central (CE; LeDoux et al. 1990b, 1991), basomedial (BM; LeDoux et al. 1990b, 1991), or basolateral (BL; LeDoux et al. 1991) amygdaloid nuclei. Neurons in the auditory cortex, which also transmit sensory information to the amygdala (Romanski and LeDoux 1992), project to the same amygdaloid nuclei as do MGN neurons (LeDoux et al. 1991). In contrast, contextual stimuli are processed in the hippocampus (Kim and Fanselow 1992; Phillips and LeDoux 1992; Maren et al. 1997, 1998), and hippocampal afferents to the amygdala synapse primarily on BL and BM neurons (Canteras and Swanson 1992; Maren and Fanselow 1995). The medial division of the CE (CEm) receives direct inputs from the LA (Smith and Pare 1994) and then projects to the lateral division of the CE (CEl; Jolkkonen and Pitkänen 1998). The CEl also receives direct projections from the basal nuclei (BA, both basolateral and basomedial nuclei; Paré et al. 1995), and projects to the brainstem areas controlling the expression of fear responses (LeDoux et al. 1988). This segregation of sensory input raises the possibility that different intra-amygdala circuitry may be used in conditioning to different CS modalities, yet very few studies have directly addressed this issue (Majidishad et al. 1996). One study indicates that both the basolateral complex (BLA; consisting of the $\mathrm{LA}$, the $\mathrm{BL}$, and the $\mathrm{BM}$ ) and the $\mathrm{CE}$ are necessary for conditioning to visual and auditory CSs in a fear-potentiated startle paradigm (Campeau and Davis 1995), but dissociations in auditory versus context conditioning have not been reported.

LEARNING \& MEMORY 8:148-155 @ 2001 by Cold Spring Harbor Laboratory Press ISSN1072-0502/01 \$5.00

$$
\begin{array}{llllllllllllllll} 
& E & A & R & N & I & N & G & \mathbf{Z} & M & E & M & O & R & Y \\
\text { www.learnmem.org } & & &
\end{array}
$$


The present experiment examines the contribution of the LA, CE, and basal nuclei to contextual and auditory fear conditioning. Because of the difficulty in obtaining bilaterally symmetric lesions of specific amygdaloid nuclei, we generated a large electrolytic lesion of the amygdala in one hemisphere, and placed discrete neurotoxic lesions of a target amygdaloid nucleus in the contralateral hemisphere of each rat. This procedure ensured that the target amygdaloid nucleus would be damaged bilaterally. We then assessed the influence of these lesions on fear conditioning to contextual and auditory CSs. Our results indicate that the LA, CE, and anterior divisions of the basal nuclei are necessary for both auditory and contextual fear conditioning, and the posterior divisions of the basal nuclei do not play a critical role in fear conditioning.

\section{RESULTS}

\section{Histology}

Rats received a unilateral electrolytic lesion, which was targeted at the entire amygdala, in one hemisphere and a small neurotoxic lesion of an individual amygdaloid nucleus in the contralateral hemisphere. Of the 106 rats, 33 were excluded from the analysis because either the electrolytic lesions were incomplete or the neurotoxic lesions were not restricted to a single amygdaloid nucleus. Some rats were reassigned to different groups based on the actual versus intended locus of the neurotoxic lesion. This resulted in the following groups: SH $(n=7)$, UNI $(n=19)$, BA $(n=24)$, LA $(n=16)$, and CE $(n=7)$. We then further grouped rats with BA damage according to whether the damage from the unilateral neurotoxic lesions was confined to the posterior re-
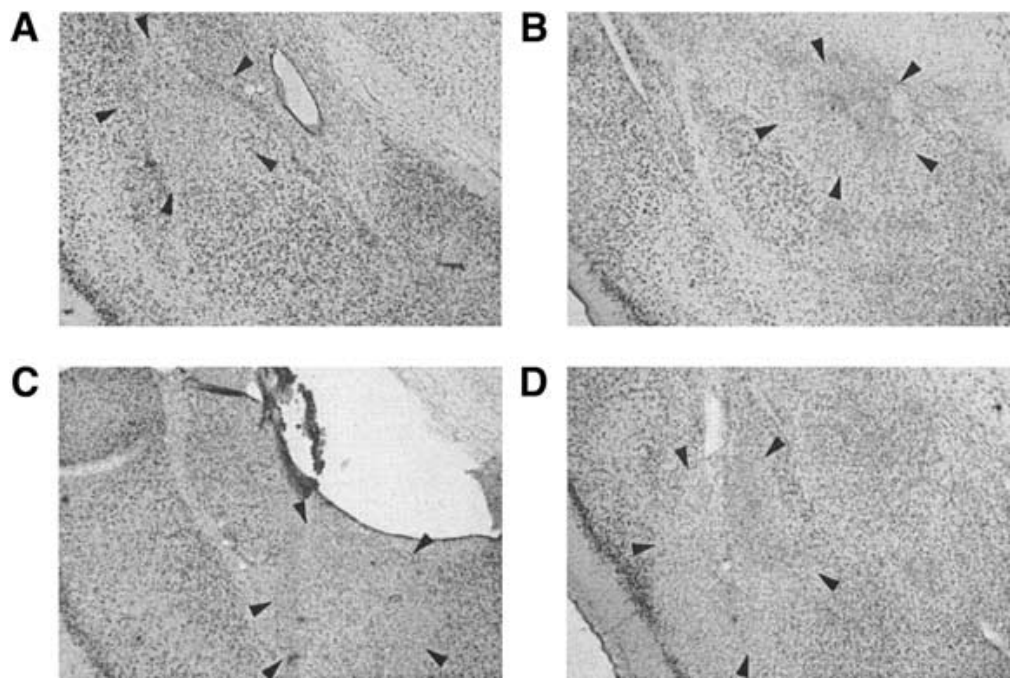

Figure 1 Neurotoxic amygdala lesions. The photomicrographs are of thioninstained coronal sections from the brains of rats with representative lesions of the $(A)$ lateral nucleus of the amygdala $(\mathrm{LA}),(B)$ central nucleus of the amygdala $(\mathrm{CE})$, and $(C, D)$ basal amygdaloid nuclei (BAp in $C$, BAa in $D$ ). gion of the basal nuclei (BAp) or extended past the intercalated amygdaloid nucleus into the anterior portion of the basal nuclei (BAa). This resulted in the following groups: BAa $(n=10)$ and BAp $(n=14)$.

Representative neurotoxic lesions from each group are shown in Figure 1. Neurotoxic lesions in the contralateral hemisphere were generally confined to the target nucleus of the amygdala; however, some of the lesions extended into adjacent structures. LA lesions typically included most of the dorsolateral and ventrolateral subnuclei, with variable damage to the ventromedial subnucleus. LA lesions also included the most ventral portion of the caudate-putamen. CE lesions included most of the lateral division of the $\mathrm{CE}$ and a large portion of the medial division of the CE, but tended to spare the most rostral aspect of the medial division. Some lesions also extended slightly into the overlying substantia innominata. Posterior lesions of the basal nuclei (BAp) caused extensive damage to the posterior divisions of the $\mathrm{BL}$ and the BM. Anterior lesions of the basal nuclei (BAa) caused limited damage to the posterior divisions of the $\mathrm{BL}$ and the $\mathrm{BM}$ and significant damage to the portions of the $\mathrm{BL}$ and the $\mathrm{BM}$ immediately anterior and posterior to the intercalated amygdaloid nucleus. Some BAp and BAa lesions extended superficially into the piriform cortex.

The extent of the amygdala lesions for all animals included in the analyses is depicted in Figure 2. Unilateral electrolytic lesions of the amygdala destroyed the LA, CE, $\mathrm{BL}$, and BM. The cortical nucleus of the amygdala was spared in all rats, whereas the medial nucleus of the amygdala received minimal damage to its lateral portion in 11 rats. A typical lesion also included moderate damage to the ventral caudate-putamen and limited damage to the endopiriform nucleus, the stria terminalis, and the piriform cortex.

\section{Behavior}

Behavioral testing was conducted in three phases. First, rats received fear conditioning, consisting of 15 tone-footshock pairings. Rats received a context and tone extinction test 24 $\mathrm{h}$ and $48 \mathrm{~h}$ following conditioning, respectively. Conditional freezing served as the measure of fear during these extinction tests. On the conditioning day, the groups did not differ in motor activity prior to footshock. This was confirmed by the absence of a significant effect of Group $\left(F_{(5,106)}=1.1\right)$ in the ANOVA performed on average activity level during the 3-min pre-shock period. We found that freezing behavior increased after fear conditioning (main effect of Training: $F_{(15,1005)}=9.0$, $P<0.0001)$. That is, rats showed an increase in freezing behavior with successive footshock 


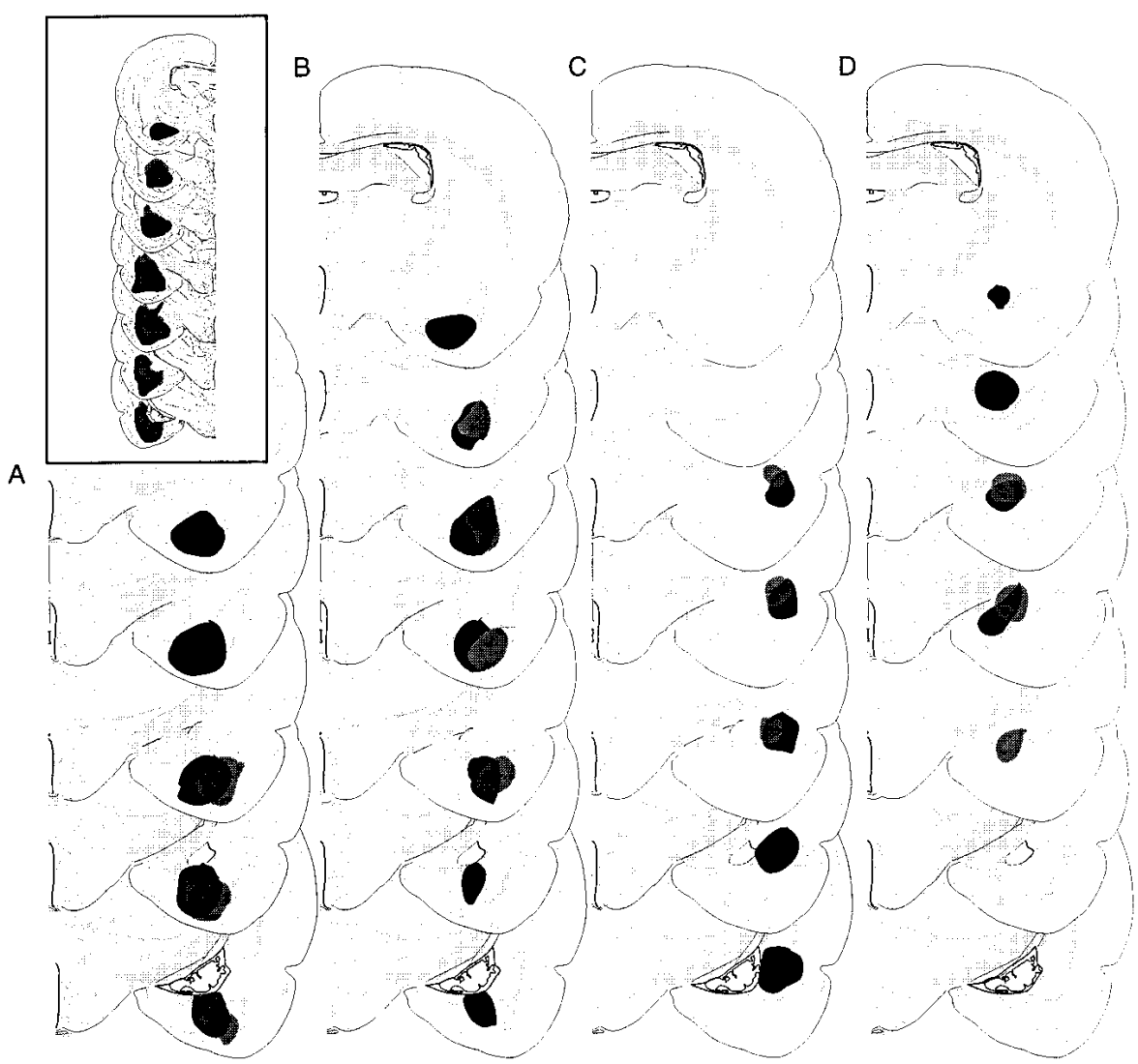

Figure 2 Schematic representation of the minimum (gray) and maximum (black) extent of damage of unilateral excitotoxic lesions to the $(A)$ posterior divisions of the basolateral and basomedial nuclei of the amygdala (BAp), $(B)$ anterior divisions of the basolateral and basomedial nuclei of the amygdala (BAa), $(C$ ) lateral nucleus of the amygdala (LA), and $(D)$ central nucleus of the amygdala (CE). The extent of unilateral electrolytic lesions of the amygdala is depicted in the inset. Brain images are adapted from Swanson (1999).

presentations. However, the groups differed in the magnitude of immediate postshock freezing during conditioning. For the purpose of comparing the groups, we analyzed the postshock test minute for which freezing behavior was maximal for each rat. As shown in Figure 3, there were group differences in maximal postshock freezing (Group $\mathrm{X}$ Period interaction: $\left.F_{(5,67)}=2.4, P<0.05\right)$. Post hoc comparisons $(P<0.05)$ indicated that maximal postshock freezing in SH and UNI rats differed from that in BAa, LA, and CE rats, but not from that in BAp rats.

Twenty-four hours after fear conditioning, the rats received an 8-min context extinction test. As shown in Figure $4 \mathrm{~A}$, control rats exhibited high levels of freezing to the contextual CS, and neurotoxic lesions of LA, CE, or BAa resulted in contextual fear deficits. This observation was confirmed by a significant main effect of Group $\left(F_{(5,67)}=5.5 ; P<0.001\right)$ in the ANOVA. Post hoc comparisons $(P<0.05)$ demonstrated that rats in the LA, CE, and BAa groups froze significantly less than rats in the UNI or SH groups (Fig. 4B). Post hoc comparisons also revealed that rats in the BAp group did not differ from the UNI control group. Rats in the UNI group froze at lower levels than animals in the $\mathrm{SH}$ group, although this effect did not reach statistical significance. These results indicate that the LA, $\mathrm{CE}$, and BAa play a critical role in contextual fear conditioning.

Twenty-four hours after the context extinction test, the rats received an 8-min tone extinction test. As shown in Figure 4C, lesions of LA, CE, or BAa produced deficits in conditional freezing to the tone CS relative to UNI controls. In contrast, lesions of BAp did not impair conditional freezing to the tone CS. This observation was confirmed by a significant main effect of Group $\left(F_{(5,67)}=5.9 ; P<.0001\right)$ and a significant Group $\mathrm{X}$ Minute interaction $\left(F_{(45,603)}=2.5 ; P<0.0001\right)$ in the ANOVA for the 8-min tone period. Post hoc comparisons (Fig. $4 \mathrm{D})$ revealed that rats with neurotoxic lesions of LA, CE, or BAa showed an impairment in toneelicited freezing relative to the UNI group. In addition, although the UNI group appeared to exhibit an impairment in freezing relative to rats in the SH group, this effect was not statistically significant. These results indicate that LA, CE, and the BAa are necessary for auditory fear conditioning.

Fear in humans is associated with unilateral increases in neuronal activity in the right amygdala (Johnsen and Hugdahl 1993; Cahill et al. 1996; Furmark et al. 1997; Morris et al. 1998), and the right amygdala also plays a greater role in the acquisition of inhibitory avoidance learning in rats (Coleman-Mesches and McGaugh 1995). For this reason, we also examined the laterality of amygdala lesions in relation to both contextual and auditory fear conditioning. As seen in Figure 5, large electrolytic lesions of the amygdaloid nuclei in the left and right hemispheres did not produce differential impairments in contextual fear conditioning per se. However, when the contralateral basal nuclei were damaged, a different pattern emerged. Specifically, damage to the posterior divisions of the basal nuclei caused significant deficits in conditioning to contextual cues only when the large electrolytic lesion of the amygdaloid nuclei was placed in the right hemisphere. These observations were con-

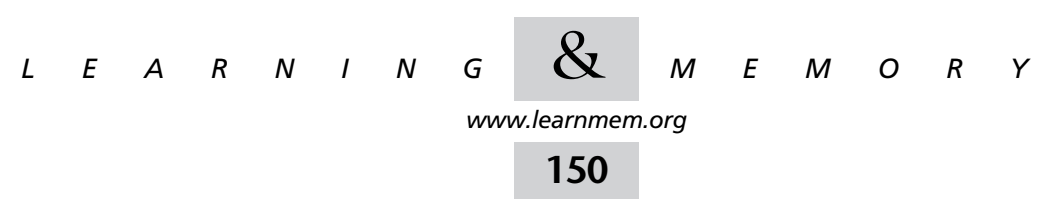




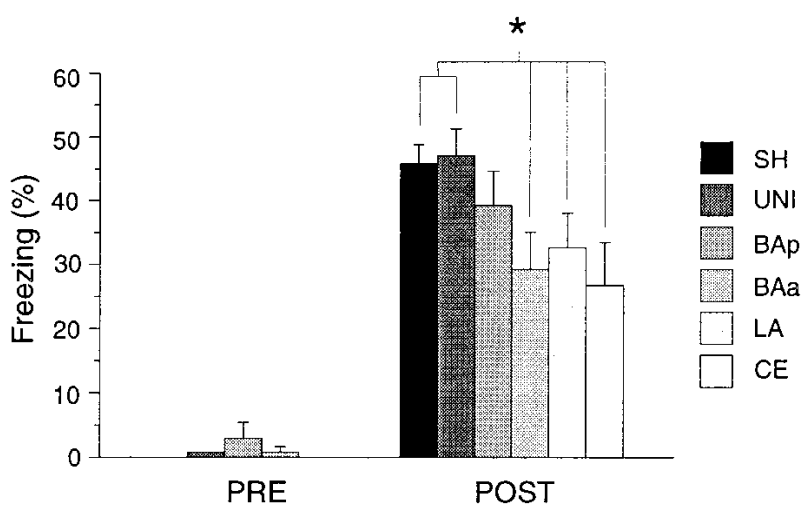

Figure 3 Conditional freezing during training. Mean $( \pm$ SEM) percentage of freezing in the $3 \mathrm{~min}$ prior to receiving tone-footshock pairings (PRE) and mean $( \pm$ SEM) percentage of freezing for the postshock period in which freezing was maximal (POST). Asterisk indicates that $P<0.05$, in planned comparisons between the UNI and SHAM groups and groups with discrete neurotoxic lesions of amygdaloid nuclei.

firmed in the ANOVA by a significant main effect of Group $\left(F_{(3,51)}=5.2 ; P<0.005\right)$, and a significant Group $\mathrm{X}$ Hemisphere interaction $\left(F_{(3,51)}=3.2 ; P<0.05\right)$. Post hoc comparisons $(P<0.05)$ also revealed a significant difference in the level of contextual fear conditioning in rats with BAp damage. This lateralized effect of BAp lesions was masked in the overall analysis presented above (see Fig. 4). In contrast to contextual conditioning, laterality was not observed for auditory fear conditioning (data not shown). Although there was a significant effect of Group on fear conditioning to auditory $\operatorname{CS}\left(F_{(3,51)}=3.5 ; P<0.05\right)$, there was a nonsignificant effect of Hemisphere $\left(F_{(1,51)}=1.3\right)$ and a nonsignificant Group X Hemisphere interaction $\left(F_{(3,51)}=0.03\right)$. Together, these data indicate that the right amygdala may play a greater role in fear conditioning to contextual CS than the left amygdala.

\section{DISCUSSION}

In the present experiment, we examined the effects of small neurotoxic amygdala lesions on contextual and auditory fear conditioning in rats. We observed that lesions confined to LA, BAa, or CE caused nonselective impairments in freezing to contextual and auditory CS. Lesions to the posterior divisions of the basal nuclei spared fear conditioning; however, a closer analysis of the data revealed that BAp lesions did impair context conditioning when the electrolytic lesion was located in the right hemisphere. None of the amygdala lesions resulted in increased motor activity during the preshock period on the training day. Therefore, the low levels of conditional freezing in rats with amygdala lesions cannot be attributed to locomotor hyperactivity. Consistent with earlier reports (LaBar et al. 1995; LaBar and LeDoux 1996), we observed moderate (although not statistically significant) deficits in both tone and context fear conditioning in rats with unilateral amygdala lesions (UNI) when compared to rats in the sham group. Collectively, these results reaffirm the important role for the LA, BA, and CE in Pavlovian fear conditioning in rats.

Our data are in agreement with many other studies highlighting the importance of the LA, BAa, and CE to the acquisition and expression of Pavlovian fear conditioning. Numerous studies have reported that lesions of the LA or CE block conditional freezing responses (LeDoux et al. 1988, 1990a; Maren et al. 1996a; Maren 1999b; Amorapanth et al. 2000), as well as other indices of conditional fear, including fear-potentiated startle (Hitchcock and Davis 1987; Campeau and Davis 1995; Lee et al. 1996) and heart rate conditioning (Kapp et al. 1979). Several studies have reported deficits in conditional fear in animals with lesions of the anterior divisions of the basal nuclei (Sananes and Davis 1992; Maren 1998). Also, BL neurons are sensitive to shifts in contextual cues (Freeman et al. 1997). Our results, however, conflict with recent reports indicating that the BL is not required for auditory fear conditioning (Killcross et al. 1997; Amorapanth et al. 2000). In one of these studies (Amorapanth et al. 2000), electrolytic lesions confined largely to the BL did not affect conditional freezing behavior to an auditory CS. In the other study (Killcross et al. 1997), neurotoxic lesions of the BLA (LA and BA) did not produce deficits in a conditioned bar-press suppression paradigm. In contrast, we have observed that rats with lesions of the anterior divisions of the basal amygdaloid nuclei (or LA) show a marked deficit in freezing to both contextual and auditory CS. One possible explanation of these discrepancies is that the BL lesions made in these reports may not have sufficiently damaged the anterior divisions of the BA, which we have found to be critical for auditory fear conditioning. Indeed, in the present study, rats that received lesions of the posterior divisions of the basal nuclei did not show deficits in conditional freezing to the auditory CS. This emphasizes the importance of lesion placement in determining the pattern of deficits observed after damaging the basal amygdaloid nuclei.

An interesting outcome of the present study relates to the lateralization of fear-conditioning circuitry in the brain. In both humans and rats, there are data indicating a more important role for the right amygdala in aversively motivated learning and memory (Johnsen and Hugdah 1993; Coleman-Mesches and McGaugh 1995; Cahill et al. 1996; Furmark et al. 1997; Morris et al. 1998). In fact, a recent report indicates a more important role for the right amygdala in the acquisition of fear conditioning in rats (Myers et al. 2000). Consistent with these results, we have found that electrolytic lesions of the right amygdala (when combined with contralateral BAp damage) produce a more severe deficit in contextual freezing than lesions of the left amygdala. Interestingly, this is not true either for auditory fear conditioning or when contralateral neurotoxic lesions are made

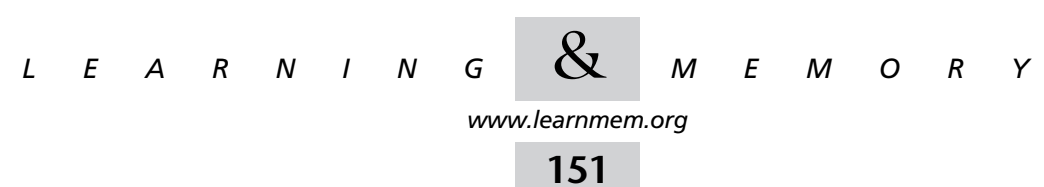


A
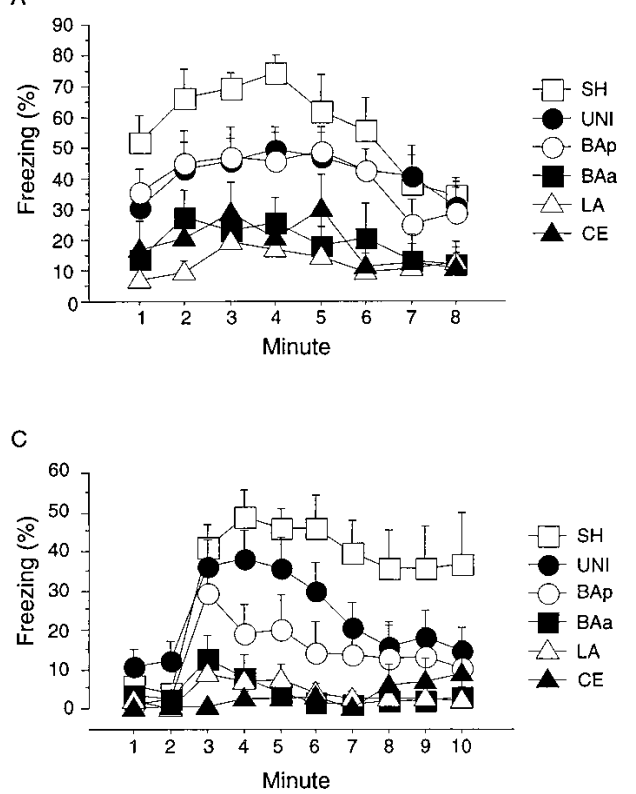

B

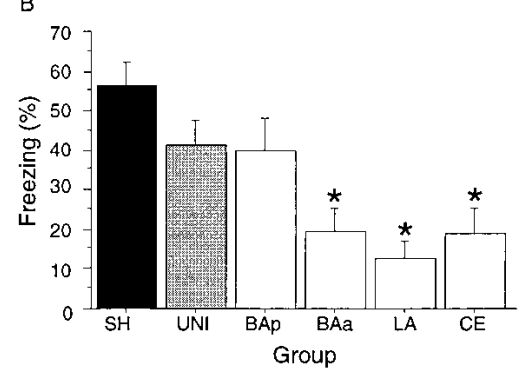

$\mathrm{D}$

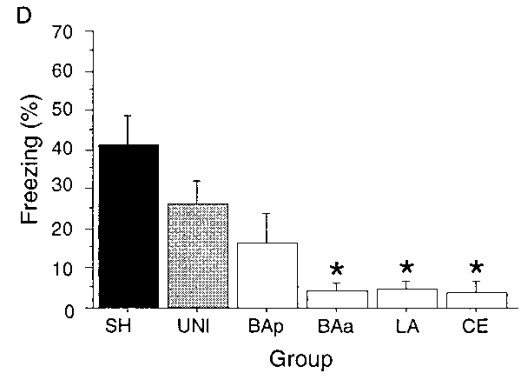

Figure 4 Pretraining neurotoxic lesions of amygdaloid nuclei and conditional freezing. (A) Mean $( \pm$ SEM) percentage of freezing during an 8-min extinction in the conditioning context. $(B)$ Mean $( \pm$ SEM) percentage of freezing averaged across the 8-min context extinction test. $(C)$ Mean $( \pm$ SEM) percentage of freezing during an 8-min tone extinction test in the B context. The tone was present during minutes 3 through 10. $(D)$ Mean $( \pm$ SEM) percentage of freezing averaged across the 8-min tone test. Asterisk indicates that $P<0.05$, in planned comparisons between the UNI group and groups with discrete neurotoxic lesions of amygdaloid nuclei.

in the LA or CE. This implies that the LA and CE may be more critical to fear conditioning than the $\mathrm{BA}$, and that the right amygdala plays a more important role than the left amygdala in the acquisition of contextual fear. Nonetheless, the lateralization of fear conditioning appears to be quite

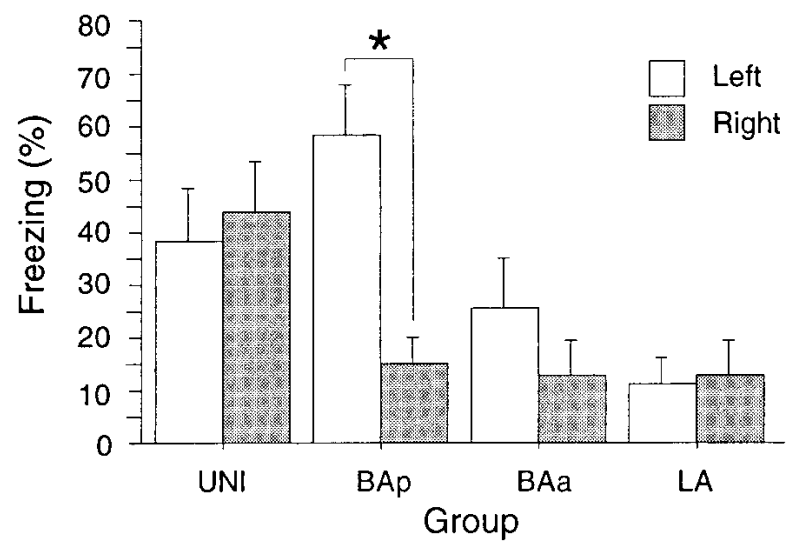

Figure 5 Hemisphere of the electrolytic amygdala lesion and contextual conditional freezing. These data are adapted from Figure $3 \mathrm{~B}$, with each group divided according to the hemisphere in which the large electrolytic lesion of the total amygdala was placed. Each group has a minimum of five rats. The CE group was not included in this analysis because there were too few rats to meet the group minimum. Asterisk indicates that $P<0.05$, in planned comparisons. subtle insofar as it is modality-specific and requires partial damage to the contralateral hemisphere to become apparent.

Because we utilized pretraining lesions, we are unable to determine whether the impairments we observed in rats with amygdala lesions are caused by problems in acquiring or expressing conditional fear memories. Indeed, an abundance of evidence indicates that the BLA plays an essential role in both acquiring and expressing Pavlovian fear conditioning (Fanselow and LeDoux 1999; Maren 1999a). Reversible inactivation of the BLA prior to training blocks the acquisition of fear conditioning (Miserendino et al. 1990; Maren et al. 1996b; Muller et al. 1997; Poremba and Gabriel 1999), and pretesting inactivation of the BLA prevents the expression of fear memories (Maren et al. 1996b; Muller et al. 1997). Nonetheless, a recent study indicates that the freezing deficits observed in rats with BLA lesions are not owing to an inability to perform the freezing response (Maren 1999b). The contribution of the $\mathrm{CE}$ to the acquisition versus expression of fear conditioning is less clear. Although the CE rapidly develops conditional increases in neuronal activity after fear conditioning (Pascoe and Kapp 1985), it is usually implicated in generating fear responses and is not thought to have an active role in acquisition (LeDoux 2000). Future research should determine whether the $\mathrm{CE}$ also contributes to the acquisition of conditional fear.

Together, our results suggest that fear conditioning to contextual and auditory CSs involves several distinct amygdaloid nuclei. By using neurotoxic lesions, we are assured that the pattern of deficits reported is caused by the destruction of neurons within the amygdaloid nuclei, rather than by damage to fibers of passage. Our data indicate that auditory and contextual fear conditioning are mediated by overlapping amygdaloid circuitry. A serial model whereby CS and US information converge in the LA and BA, are associated via a synaptic plasticity mechanism such as longterm potentiation (Fanselow and LeDoux 1999; Maren 1999a), and are relayed to the CE for the generation of conditional freezing is consistent with the present results (Fig. 6). Further studies are required to determine where within this neural circuit the critical plasticity underlying fear conditioning resides.

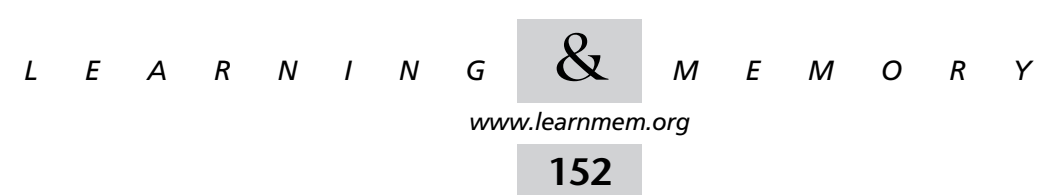




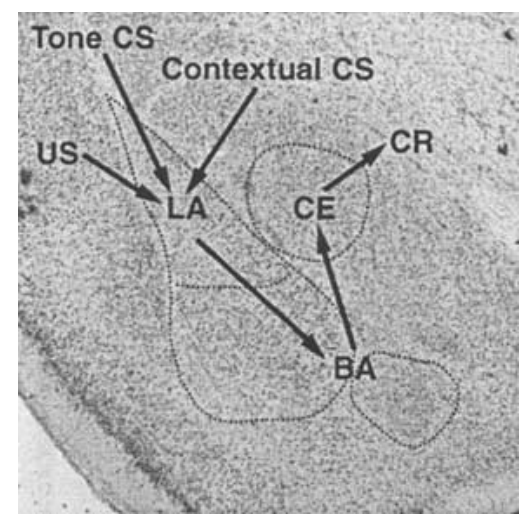

Figure 6 Anatomical model of fear conditioning circuits within the amygdala. Contextual and auditory CS converge on LA neurons, where they come into association with the footshock US. Indirect projections from the LA to the CE via the basal nuclei mediate expression of both tone-US and context-US associations.

\section{MATERIALS AND METHODS}

\section{Subjects}

One hundred and six adult male Long-Evans rats (200-224 g) were obtained from a commercial supplier (Harlan Sprague-Dawley) and individually housed in Plexiglas hanging cages with free access to food and tap water. The room was placed on a $14: 10$-h light-dark cycle (lights on at 7:00 a.m.). Rats were handled for $30 \mathrm{sec} / \mathrm{d}$ for 5 d to acclimate them to the experimenters.

\section{Surgery}

One week before behavioral testing, rats received either amygdala lesions or sham surgery. Experimental groups received a large electrolytic amygdala lesion in one hemisphere, and a nucleus-specific neurotoxic amygdala lesion in the contralateral hemisphere. Control groups received either sham surgery, or an electrolytic amygdala lesion in one hemisphere. Lesion placements were counterbalanced across hemispheres. Because it was difficult to generate lesions that were restricted to the BL without also damaging the BM in pilot experiments, we elected to target both nuclei. This resulted in five experimental groups: lateral nucleus (LA; $n=16$ ); central nucleus (CE; $n=16$ ); basal nuclei (BA; $n=26$ ); large, unilateral amygdala lesions (UNI; $n=12$ ); and sham surgery (SH; $n=8$ ).

Rats were anaesthetized with sodium pentobarbital $(65 \mathrm{mg} / \mathrm{kg}$ i.p.) and were administered atropine methyl nitrate $(0.4 \mathrm{mg} / \mathrm{kg}$ i.p.) to prevent airway obstruction. After mounting in a stereotaxic apparatus (Kopf Instruments), the scalp was incised and retracted. The skull was leveled by placing lambda and bregma in the same horizontal plane. Small burr holes were drilled in the skull for placement of injection cannulas and/or electrodes. Electrolytic amygdala lesions targeted the $\mathrm{LA}, \mathrm{CE}, \mathrm{BL}$, and $\mathrm{BM}$ in one hemisphere. An Epoxylite-insulated monopolar electrode with a 500- $\mu \mathrm{m}$ exposed tip was used to deliver anodal current $(1.0 \mathrm{~mA}, 23 \mathrm{sec})$ at two ipsilateral sites: -2.3 posterior to bregma, $+/-4.5$ lateral to bregma, -7.5 ventral to dura; and -2.8 posterior to bregma, $+/-5.0$ lateral to bregma, -7.5 ventral to dura. Neurotoxic lesions of the LA and basal nuclei (LA: $2.6 \mathrm{~mm}$ posterior to bregma, $5.1 \mathrm{~mm}$ lateral to bregma, $6.5 \mathrm{~mm}$ ventral to dura) (BA: $3.5 \mathrm{~mm}$ posterior to bregma, $5.0 \mathrm{~mm}$ lateral to bregma, $8.0 \mathrm{~mm}$ ventral to dura; $3.6 \mathrm{~mm}$ posterior to bregma, $5.1 \mathrm{~mm}$ lateral to bregma, $8.1 \mathrm{~mm}$ ventral to dura; 2.4 $\mathrm{mm}$ posterior to bregma, $4.4 \mathrm{~mm}$ lateral to bregma, $8.1 \mathrm{~mm}$ ventral to dura) were made using $N$-methyl-D-aspartate (NMDA; $20 \mathrm{mg} / \mathrm{mL}$; Sigma). Neurotoxic lesions of the CE (2.3 $\mathrm{mm}$ posterior to bregma, $4.2 \mathrm{~mm}$ lateral to bregma, $7.5 \mathrm{~mm}$ ventral to dura) were made with ibotenic acid (IBO; $10 \mathrm{mg} / \mathrm{mL}$; Sigma). The neurotoxins were diluted in 0.1 M PBS ( $\mathrm{pH} 7.4$ ) and infused through 28-gauge injection cannulas $(0.1 \mu \mathrm{L} / \mathrm{min}$ for $1 \mathrm{~min})$ that were attached to an infusion pump (Harvard Apparatus) with polyethylene tubing (PE-20; A-M Systems). The total volume infused at each injection site was therefore $0.1 \mu \mathrm{L}$. Five minutes was allowed for diffusion of the drug before the injector needle was removed. Sham animals received a scalp incision and skull holes. After surgery, the incision was closed with stainless steel wound clips, and the animals were returned to their home cages.

\section{Behavioral Apparatus}

Eight identical observation chambers $(30 \times 24 \times 21 \mathrm{~cm}$; MED-Associates) were used for all conditioning and extinction testing. The chambers were constructed of aluminum (two side walls) and Plexiglas (rear wall, ceiling, and hinged front door), and situated in sound-attenuating cabinets in an isolated room. The floor of each chamber consisted of 19 stainless steel rods ( $4 \mathrm{~mm}$ diameter) spaced $1.5 \mathrm{~cm}$ apart (center to center). The rods were wired to a shock source and solid-state grid scrambler (MED-Associates) for the delivery of footshock unconditional stimuli (US). A speaker for delivering acoustic stimuli and a small stimulus light $(15 \mathrm{~W})$ were mounted to the walls of each chamber.

Each conditioning chamber rested on a load-cell platform that recorded chamber displacement in response to each rat's motor activity. The output of each chamber's load cell was amplified to a level that was previously determined to optimize the detection of freezing behavior (Maren 1998). The load-cell amplifier output from each chamber was digitized at $5 \mathrm{~Hz}$ (yielding 300 observations/min per rat) and acquired on-line using Threshold Activity software (MED-Associates). The raw load-cell output was averaged on a minute-by-minute basis and used to examine locomotor activity. Freezing was quantified by calculating the number of observations below a freezing threshold. Freezing was scored only if a rat was immobile for $1 \mathrm{sec}$ or longer; freezing was thus scored only for five or more contiguous observations.

Fear conditioning occurred in Context A. In this context, the chambers were cleaned with a $5 \%$ ammonium hydroxide solution, and stainless steel pans with a thin layer of the same solution were placed under the grid floors before rats were placed in the chambers. Illumination was provided by both the room lights and the small light in each chamber, and the cabinet doors remained open. Background noise ( $65 \mathrm{~dB}$, A-scale) was supplied by ventilation fans in each cabinet. Context extinction testing occurred in Context A, whereas tone extinction testing occurred in a different context (Context B). The same chambers described above were used for Context B, except that $1 \%$ acetic acid was used to clean the chambers and was placed in the pans under the grid floor. Illumination was provided only by a $40-\mathrm{W}$ red light in the room, and the cabinet doors were closed. The ventilation fans were also turned off

\section{Procedure}

One week after surgery, the rats were transported to the laboratory in squads of eight and placed in the conditioning chambers for training in the A context. Three minutes after placement in the chambers, the rats received 15 tone $(85 \mathrm{~dB}, 2 \mathrm{kHz}, 10 \mathrm{sec})$-footshock (2 sec, $1.0 \mathrm{~mA}$ ) pairings (70-sec intertrial interval). The rats 
were returned to their home cages $1 \mathrm{~min}$ after the final shock. Fear conditioning to the context was assessed by returning the rats to the conditioning chambers $24 \mathrm{~h}$ later and assessing freezing during an 8-min extinction test in Context A. Twenty-four hours after the context test, fear conditioning to the tone was assessed by placing the rats in a novel context (Context $\mathrm{B}$ ) and assessing freezing during an 8-min tone $(85 \mathrm{~dB}, 2 \mathrm{kHz})$. Activity and freezing data were collected during both training and testing using the automated system described above.

\section{Histology}

Histological verification of the brain lesions was performed after behavioral testing. Rats were perfused across the heart with $0.9 \%$ saline followed by $10 \%$ formalin. Brains were removed from the skull and postfixed in 10\% formalin for $2 \mathrm{~d}$ and $10 \%$ formalin/30\% sucrose until sectioning. Coronal sections ( $40 \mu \mathrm{m}$ thick, taken every $80 \mu \mathrm{m})$ were cut on a cryostat $\left(-18^{\circ} \mathrm{C}\right)$ and wet-mounted on glass microscope slides with $70 \%$ ethanol. After drying, sections were stained with $0.25 \%$ thionin to visualize cell bodies. Cannula placements were reconstructed on stereotaxic atlas templates (Swanson 1999).

\section{Data Analysis}

For each session, the freezing data were transformed to a percentage of the total observations, a probability estimate that is amenable to analysis with parametric statistics. These probability estimates of freezing were analyzed using ANOVA. Post hoc comparisons in the form of Fisher's PLSD tests were performed after a significant omnibus $F$-ratio. All data are represented as the mean \pm SEM.

\section{ACKNOWLEDGMENTS}

This research was supported by a grant from the National Institute of Mental Health (MH57865) to S.M. K.A.G. is a Howard Hughes predoctoral fellow.

The publication costs of this article were defrayed in part by payment of page charges. This article must therefore be hereby marked "advertisement" in accordance with 18 USC section 1734 solely to indicate this fact.

\section{REFERENCES}

Amorapanth, P., LeDoux, J.E., and Nader, K. 2000. Different lateral amygdala outputs mediate reactions and actions elicited by a fear-arousing stimulus. Nature Neurosci. 3: 74-79.

Cahill, L., Haier, R.J., Fallon, J., Alkire, M.T., Tang, C., Keator, D., Wu, J., and McGaugh, J.L. 1996. Amygdala activity at encoding correlated with long-term free recall of emotional information. Proc. Natl. Acad. Sci 93: 8016-8021.

Campeau, S. and Davis, M. 1995. Involvement of the central nucleus and basolateral complex of the amygdala in fear conditioning measured with fear-potentiated startle in rats trained concurrently with auditory and visual conditioned stimuli. J. Neurosci. 15: 2301-2311.

Canteras, N.S. and Swanson, L.W. 1992. Projections of the ventral subiculum to the amygdala, septum, and hypothalamus: A PHAL anterograde tract-tracing study in the rat. J. Comp. Neurol. 324: 180-194.

Coleman-Mesches, K. and McGaugh, J.L. 1995. Differential effects of pretraining inactivation of the right or left amygdala on retention of inhibitory avoidance training. Behav. Neurosci. 109: 642-647.

Davis, M. 1992. The role of the amygdala in fear and anxiety. Ann. Rev. Neurosci. 15: 353-375.

Doron, N.N. and LeDoux, J.E. 1999. Organization of projections to the lateral amygdala from auditory and visual areas of the thalamus in the rat. J. Comp. Neurol. 412: 383-409.
Falls, W.A. and Davis, M. 1995. Lesions of the central nucleus of the amygdala block conditioned excitation, but not conditioned inhibition of fear as measured with the fear-potentiated startle effect. Behav. Neurosci. 109: 379-387.

Fanselow, M.S. 1994. Neural organization of the defensive behavior system responsible for fear. Psychon. Bull. Rev. 1: 429-438.

Fanselow, M.S. and LeDoux, J.E. 1999. Why we think plasticity underlying Pavlovian fear conditioning occurs in the basolateral amygdala. Neuron 23: 229-232.

Freeman, J.H., Jr., Weible, A., Rossi, J., and Gabriel, M. 1997. Lesions of the entorhinal cortex disrupt behavioral and neuronal responses to context change during extinction of discriminative avoidance behavior. Exp. Brain Res. 115: 445-457.

Furmark, T., Fischer, H., Wik, G., Larsson, M., and Fredrikson, M. 1997. The amygdala and individual differences in human fear conditioning. Neuroreport 8: 3957-3960.

Hitchcock, J.M. and Davis, M. 1987. Fear-potentiated startle using an auditory conditioned stimulus: Effect of lesions of the amygdala. Physiol. Behav. 39: 403-408.

Johnsen, B.H. and Hugdahl, K. 1993. Right hemisphere representation of autonomic conditioning to facial emotional expressions. Psychophysiol. 30: 274-278.

Jolkkonen, E. and Pitkänen, A. 1998. Intrinsic connections of the rat amygdaloid complex: Projections originating in the central nucleus. $J$. Comp. Neurol. 395: 53-72.

Kapp, B.S., Frysinger, R.C., Gallagher, M., and Haselton, J. 1979. Amygdala central nucleus lesions: Effect on heart rate conditioning in the rabbit. Physiol. Behav. 23: 1109-1117.

Killcross, S., Robbins, T.W., and Everitt, B.J. 1997. Different types of fear-conditioned behaviour mediated by separate nuclei within amygdala. Nature 388: 377-380.

Kim, J.J. and Fanselow, M.S. 1992. Modality-specific retrograde amnesia of fear. Science 256: 675-677.

LaBar, K.S. and LeDoux, J.E. 1996. Partial disruption of fear conditioning in rats with unilateral amygdala damage: Correspondence with unilateral temporal lobectomy in humans. Behav. Neurosci. 110: 991-1997.

LaBar, K.S., LeDoux, J.E., Spencer, D.D., and Phelps, E.A. 1995. Impaired fear conditioning following unilateral temporal lobectomy in humans J. Neurosci. 15: 6846-6855.

LeDoux, J.E. 1995. Emotion: Clues from the brain. Ann. Rev. Psychol. 46: 209-235.

2000. Emotion circuits in the brain. Ann. Rev. Psychol. 23: $155-184$.

LeDoux, J.E., Iwata, J., Cicchetti, P., and Reis, D.J. 1988. Different projections of the central amygdaloid nucleus mediate autonomic and behavioral correlates of conditioned fear. J. Neurosci. 8: 2517-2529.

LeDoux, J.E., Cicchetti, P., Xagoraris, A., and Romanski, L.M. 1990a. The lateral amygdaloid nucleus: Sensory interface of the amygdala in fear conditioning. J. Neurosci. 10: 1062-1069.

LeDoux, J.E., Farb, C., and Ruggiero, D.A. 1990b. Topographic organization of neurons in the acoustic thalamus that project to the amygdala. J. Neurosci. 10: 1043-1054.

LeDoux, J.E., Farb, C., and Romanski, L.M. 1991. Overlapping projections to the amygdala and striatum from auditory processing areas of the thalamus and cortex. Neurosci. Lett. 134: 139-144.

Lee, H., Walker, D., and Davis, M. 1996. Lack of a temporal gradient of retrograde amnesia following NMDA-induced lesions of the basolatera amygdala assessed with the fear-potentiated startle paradigm. Behav. Neurosci. 110: 836-869.

Majidishad, P., Pelli, D.G., and LeDoux, J.E. 1996. Disruption of fear conditioning to contextual stimuli but not to a tone by lesions of the accessory basal nucleus of the amygdala. Soc. Neurosci. Abstr. 22: 1116 .

Maren, S. 1998. Overtraining does not mitigate contextual fear conditioning deficits produced by neurotoxic lesions of the basolateral amygdala. J. Neurosci. 18: 3088-3097.

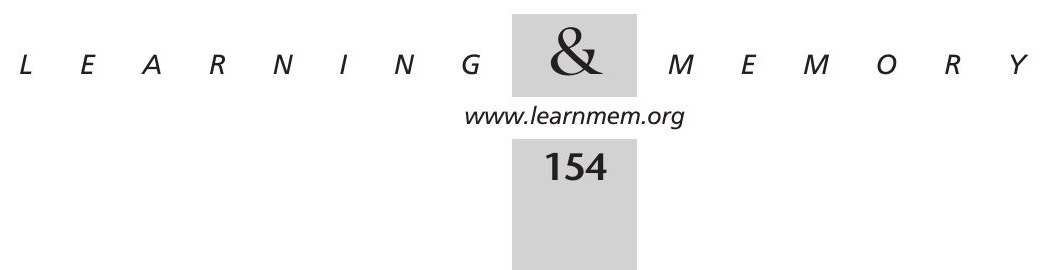


- 1999a. Long-term potentiation in the amygdala: A mechanism for emotional learning and memory. Trends Neurosci. 22: 561-567. - 1999b. Neurotoxic basolateral amygdala lesions impair learning and memory but not the performance of conditional fear in rat. $J$. Neurosci. 19: 8696-703.

. 2000. Auditory fear conditioning increases CS-elicited spike firing in lateral amygdala neurons even after extensive overtraining. Eur. $J$. Neurosci. 12: 4047-4054

. 2001. Neurobiology of Pavlovian fear conditioning. Ann. Rev. Neurosci. 24: 897-931.

Maren, S. and Fanselow, M.S. 1995. Synaptic plasticity in the basolateral amygdala induced by hippocampal formation stimulation in vivo. $J$. Neurosci. 15: 7548-7564.

Maren, S., Poremba, A., and Gabriel, M. 1991. Basolateral amygdaloid multi-unit neuronal correlates of discriminative avoidance learning in rabbits. Brain Res. 549: 311-316.

Maren, S., Aharonov, G., and Fanselow, M.S. 1996a. Retrograde abolition of conditional fear after excitotoxic lesions in the basolateral amygdala of rats: Absence of a temporal gradient. Behav. Neurosci. 110: $718-726$

Maren, S., Aharonov, G., Stote, D.L., and Fanselow, M.S. 1996b. $N$-Methyl-D-aspartate receptors in the basolateral amygdala are required for both acquisition and expression of conditional fear in rats. Behav. Neurosci. 110: 1365-1374.

Maren, S., Aharonov, G., and Fanselow, M.S. 1997. Neurotoxic lesions of the dorsal hippocampus and Pavlovian fear conditioning in rats. Behav. Brain Res. 88: 261-274.

Maren, S., Anagnostaras, S.G., and Fanselow, M.S. 1998. The startled seahorse: Is the hippocampus necessary for contextual fear conditioning? Trends Cog. Sci. 2: 39-42.

Miserendino, M.J., Sananes, C.B., Melia, K.R., and Davis, M. 1990. Blocking of acquisition but not expression of conditioned fear-potentiated startle by NMDA antagonists in the amygdala. Nature 345: 716-718.

Morris, J.S., Öhman, A., and Dolan, R.J. 1998. Conscious and unconscious emotional learning in the human amygdala. Nature 293: 467-470.

Muller, J., Corodimas, K.P., Fridel, Z., and LeDoux, J.E. 1997. Functional inactivation of the lateral and basal nuclei of the amygdala by muscimol infusion prevents fear conditioning to an explicit conditioned stimulus and to contextual stimuli. Behav. Neurosci. 111: 683-691.

Myers, K.M, Baker, K.B., Lee, H.J., and Kim, J.J. 2000. Unilateral amygdala differences in classical fear conditioning: Evidence for greater involvement of right amygdala. Soc. Neurosci. Abs. 30: 36 .

Paré, D., Smith, Y., and Paré, J.F. 1995. Intra-amygdaloid projections of the basolateral and basomedial nuclei in the cat: Phaseolus vulgaris-leucoagglutinin anterograde tracing at the light and electron microscopic level. Neurosci. 69: 567-583.

Pascoe, J.P. and Kapp, B.S. 1985. Electrophysiological characteristics of amygdaloid central nucleus neurons during Pavlovian fear conditioning in the rabbit. Behav. Brain Res. 16: 117-133.

Phillips, R.G. and LeDoux, J.E. 1992. Differential contribution of amygdala and hippocampus to cued and contextual fear conditioning. Behav. Neurosci. 106: 274-285.

Pitkänen, A., Savander, V., and LeDoux, J.E. 1997. Organization of intra-amygdaloid circuitries in the rat: An emerging framework for understanding functions of the amygdala. Trends Neurosci. 20: 517-523.

Poremba, A. and Gabriel, M. 1999. Amygdala neurons mediate acquisition but not maintenance of instrumental avoidance behavior in rabbits. $J$. Neurosci. 19: 9635-9641.

Quirk, G.J., Repa, J.C., and LeDoux, J.E. 1995. Fear conditioning enhances short-latency auditory responses of lateral amygdala neurons: Parallel recordings in the freely behaving rat. Neuron 15: 1029-1039.

Quirk, G.J., Armony, J.L., and LeDoux, J.E. 1997. Fear conditioning enhances different temporal components of tone-evoked spike trains in auditory cortex and lateral amygdala. Neuron 19: 613-624.

Romanski, L.M. and LeDoux, J.E. 1992. Equipotentiality of thalamo-amygdala and thalamo-cortico-amygdala projections as auditory conditioned stimulus pathways. J. Neurosci. 12: 4501-4509.

Romanski, L.M., LeDoux, J.E., Clugnet, M.C., and Bordi, F. 1993. Somatosensory and auditory convergence in the lateral nucleus of the amygdala. Behav. Neurosci. 107: 444-450.

Sananes, C.B. and Davis, M. 1992. N-Methyl-D-aspartate lesions of the lateral and basolateral nuclei of the amygdala block fear-potentiated startle and shock sensitization of startle. Behav. Neurosci. 106: 72-80.

Shi, C. and Davis, M. 1999. Pain pathways involved in fear conditioning measured with fear-potentiated startle: Lesion studies. J. Neurosci. 19: $420-430$.

Smith, Y. and Paré, D. 1994. Intra-amygdaloid projections of the lateral nucleus in the cat: PHA-L anterograde labeling combined with postembedding GABA and glutamate immunocytochemistry. J. Comp. Neurol. 342: 232-248.

Swanson, L.W. 1999. Brain maps: Structure of the rat brain, 2nd ed. Elsevier, Amsterdam.

Swanson, L.W. and Petrovich, G.D. 1998. What is the amygdala? Trends Neurosci. 21: 323-331.

Received October 31, 2000; accepted in revised form April 6, 2001. 


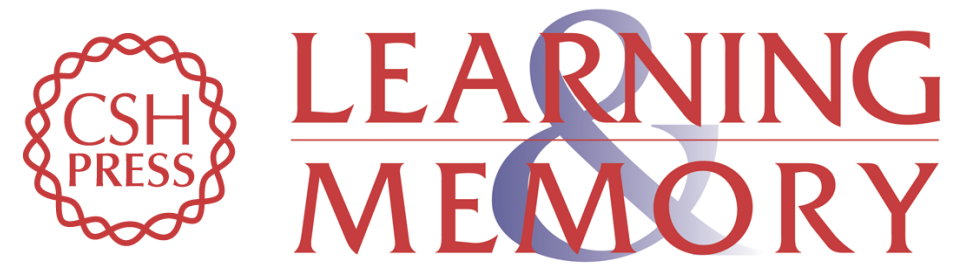

\section{Contextual and Auditory Fear Conditioning are Mediated by the Lateral, Basal, and Central Amygdaloid Nuclei in Rats}

Ki A. Goosens and Stephen Maren

Learn. Mem. 2001, 8:

Access the most recent version at doi:10.1101//m.37601

References This article cites 54 articles, 13 of which can be accessed free at: http://learnmem.cshlp.org/content/8/3/148.full.html\#ref-list-1

License

Email Alerting Receive free email alerts when new articles cite this article - sign up in the box at the Service top right corner of the article or click here. 